\title{
A comparative microbiological study of surface, aspirate and core tonsillar flora in chronic tonsillitis
}

\author{
Sriram G. ${ }^{1}$, Ganeshbala A. ${ }^{2}$, Swetha LM. ${ }^{3}$, Jayendiran S. ${ }^{4}$ \\ ${ }^{1}$ Dr. Sriram Govindaraj, Assistant Professor, ${ }^{2}$ Dr. Ganeshbala Arivazhagan, Professor, ${ }^{3}$ Dr. Swetha Lakshmi M., \\ Postgraduate, ${ }^{4}$ Dr. Jayendiran S., Senior Resident, all authors are affiliated with Vinayaka Missions Medical College and \\ Hospital Karaikal, Puducherry, India.
}

Corresponding Author: Dr. Ganeshbala Arivazhagan, Professor, Vinayaka Missions Medical College and Hospital Karaikal, Puducherry, India, E-mail-gbala.mbbs@gmail.com

\begin{abstract}
Background: Chronic tonsillitis is most common condition which affects school going children. Improper use of antibiotic among the common population has led to many drug resistant organisms; therefore, it is necessary to study the antimicrobial susceptibility pattern before treating the patient with Chronic tonsillitis. Aim of the study is to determine whether fine-needle aspiration of tonsil, gives a representative picture of deep tonsil flora in chronic tonsillitis, as assessed by subsequent culture from the core of the resected tonsils, and to compare the findings of fine needle tonsils aspiration, with findings from a routine superficial tonsil surface swab. Methods: Study conducted at ENT department of Vinayaka mission medical college, Karaikal, Pondicherry over a period of 1year (June 2018 to May 2019). 77 patients were operated for chronic tonsillitis were included in the study. 3 swabs were collected from surface of tonsil. Tonsil aspiration was done using a 10-mL syringe with an18-gauge needle and swab from core of tonsil was collected for culture and sensitivity. Bacterial isolates were identified using standard methods and antibiotic susceptibility testing were done. Results: Group B hemolytic streptococcus, Streptococcus pneumonae and Staphlococcus aueus were the predominant microbes isolated in the aspirate and tonsil core tissue in outpatient population. Whereas Alpha hemolytic streptoccus and Group B hemolytic streptococcus were predominantly seen in tonsillar surface. Conclusions: Tonsil fine needle aspiration helps in diagnosis of Chronic tonsillitis and culture based antibiotic therapy. Due to which Tonsillectomy procedures can be avoided in Chronic tonsillitis patients.
\end{abstract}

Keywords: Chronic tonsillitis, Bacteriological profile, Antibiogram, Tonsillectomy

\section{Introduction}

Palatine Tonsils, commonly called "The Tonsils" are collection of sub-epithelial lymphoid tissue in the oropharynx between the anterior and posterior pillar on both sides. Proteins produced by the immune cells in the tonsils help to kill the bacteria and prevent throat and lung infections. Tonsills are prone for recurrent Viral and Bacterial infection, which lead to Chronic Tonsillitis, which in turn is a very common disease in school going children [1].

The highest immunological activity of the tonsil is found between the age group of $3 y r$ s to 10 years. Hence, the tonsils are more prominent during this period and later demonstrate age-dependent involution [2]. Predominant symptoms of Chronic tonsillitis include,

Manuscript received: $14^{\text {th }}$ August 2019

Reviewed: $24^{\text {th }}$ August 2019

Author Corrected: $30^{\text {th }}$ August 2019

Accepted for Publication: $6^{\text {th }}$ September 2019 sore throat, difficulty in swallowing, ear ache and fever with or without a history of upper respiratory tract infection. Chronic tonsillitis patients have persistent congestion of pillars, soft palate and uvula with red and swollen tonsils. Tonsillar diseases will affect other anatomical-related structures like, the middle ear cleft, paranasal sinuses, and upper Aerodigestive tract $[2,3]$.

In chronic tonsillitis, the culture of organisms obtained from the tonsillar surface, might not be the infecting organism but could be the colonizing species. So, core culture from the tonsils would be more reliable.

Thus understanding the microbiological flora of chronic tonsillitis, from the deep core tissue is an important step in its management [1]. Surface tonsillar swabs are used as a guide in the selection of antibiotics in chronic tonsillitis. However, their use may lead to incorrect 


\section{Original Research Article}

conclusions, since several studies indicate a marked discrepancy in the external and the core tonsillar pathogenic flora $[4,5,6]$.

Better management of Chronic tonsillitis requires understanding of the exact Microbiological flora and their sensitivity, involved in the disease process.
Objective of this study- a) Is to determine whether fine-needle aspiration of tonsil, gives a representative picture of deep tonsil flora in chronic tonsillitis, as assessed by subsequent culture from the core of the resected tonsils, and b)To compare the findings of fine needle tonsils aspiration, with findings from a routine superficial tonsil surface swab.

\section{Methods}

Type of study and Period of study: It is a prospective study conducted in ENT department of VMMC, Karaikal, Pondicherry over a period of 1 year (June 2018 to May 2019).

The materials for the present study, were collected from patients (male and female) suffering from chronic tonsillitis among the age group 5-20 years, attending ENT OPD at Vinayaka Mission's Medical College and Hospital, Karaikal, Pondicherry, with history of recurrent throat infection (more than 5 episode per year) in past 2 years. Samples were collected during the study period, fulfilling the following inclusion and exclusion criteria.

\section{Inclusion criteria}

- Age between 5yrs and 20 yrs

- Patients suffering from repeated throat infection for more than 2years duration.

- Patients should not have received systemic antibiotics for last 3 months.

\section{Exclusion criteria}

- Acute tonsillitis

- Peritonsillar abscess

- Patients with upper respiratory tract infection

- Bleeding disorders, e.g. leukaemia, purpura, aplastic anaemia or haemophilia.

A through clinical examination of Ear, Nose and Throat was carried out.

Sample collection for microbiological procedures: Under full aseptic precaution, a tonsillar surface swab was obtained from the tonsil by rotating a sterile cotton wool swab sticks over the surface of the tonsil without touching the other parts of oro-pharynx.

Three such swabs were taken. One swab was used for Gram stain and another two swabs were sent for bacteriological and mycological culture.

Next, tonsil aspiration done, using aseptic precaution, using a 10-ml syringe with, fine cyotology needle, with an average of two passes, using constant suction (Fig 1). Aspirated specimen sent to microbiology lab for culture and sensitivity examination.

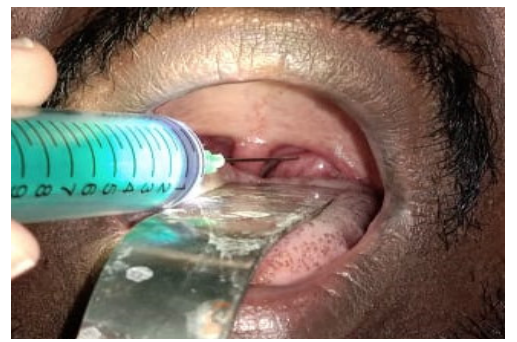

Figure 1-Fine needle aspiration from tonsil core 


\section{Original Research Article}

Tonsillectomy was done under general anesthesia, by dissection and snare method. Tonsills are placed in a sterile container, and dispatched along with the swab and aspirate to the microbiology laboratory. Tonsil core culture was prepared, using aseptic, non-touch technique. The tonsils were washed in sterile saline and placed in a sterile Petri dish, and the deep (cut) surface of the tonsil was cauterized using a flamed scalpel. The tonsil was next bisected through the cauterized surface using a sterile scalpel, and the core was sampled using a sterile swab. This swab was cultured on both Blood agar and Chocolate agar, then incubated at $37{ }^{\circ} \mathrm{C}$ for $18 \mathrm{hrs}$ to $24 \mathrm{hrs}$. Immediately on receipt of the aspirate in the laboratory, the needle was removed, and few drops of fluid were inoculated on blood agar and chocolate agar. Isolated organism was identified by standard microbiological procedures (Fig 2). Antibiotic susceptibility testing of the organisms was done by Kirby Bauer disk diffusion method (Donald C. Sockett DVM) in Muller Hinton agar. The plates were read after overnight incubation at $37^{\circ} \mathrm{c}$, by measuring the zone of inhibition around the antibiotic discs and reference tables were used to determine if the bacteria are sensitive (S), intermediate (I) or resistant (R)to the antimicrobial drugs as per CLSI (Clinical Laboratory Standards Institute) guidelines.

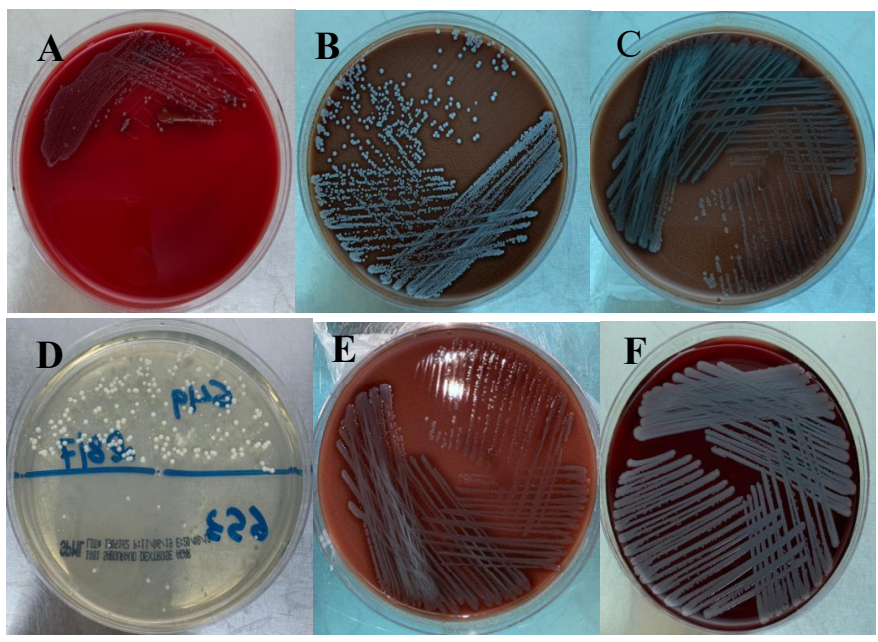

Figure 2: (A)- Blood agar showing colonies of Staphlococcus epidermis (B)-Chocolate agar showing colonies of Staphlococcus aureus (C)-Chocolate agar showing colonies of Pseudomonas aeroginosa (D)-Candida albicans (E)Chocolate agar showing colonies of Streptococcus pneumoniae (F)- Blood agar showing colonies of Hemophilus influenza

\section{Results}

A total of 77 patients (34 males and 43 females were operated for chronic tonsillitis from the period of June 2018 to May 2019. Duration of symptoms due to tonsillar disease ranged 1 to 28 months.

Table No 1: Distribution of study subjects

\begin{tabular}{|c|c|}
\hline & No. of patients \\
\hline Male & 34 \\
\hline Female & 43 \\
\hline Total & $\mathbf{7 7}$ \\
\hline
\end{tabular}

154 tonsils (both tonsils from each patient) were dissected and processed for microbiological analysis, out of which 97 tonsils yielded growth of organisms. In 50 tonsils mono-microbial growth was observed and remaining 47 showed polymicrobial growth (more than one organism).

Table 2: Mono \& poly bacterial involvement

\begin{tabular}{|c|c|}
\hline & No. of tonsils \\
\hline Mono-bacterial & 50 \\
\hline Poly-bacterial & 47 \\
\hline Sterile & 57 \\
\hline Total & $\mathbf{1 5 4}$ \\
\hline
\end{tabular}


Table 3 shows different organisms isolated from 97 tonsils. Group B hemolytic streptococcus, Streptococcus pneumonae and Staphlococcus aueus were the predominant microbes isolated in the aspirate and tonsil core tissue in outpatient population.

Whereas Alpha hemolytic streptoccus and Group B hemolytic streptococcus were predominantly seen in tonsillar surface.

Table-3: Organisms isolated from excised tonsils

\begin{tabular}{|c|c|c|c|}
\hline \multirow[b]{2}{*}{ Organism } & \multicolumn{3}{|c|}{ Number of isolates } \\
\hline & Surface & Aspirate & Core \\
\hline \multicolumn{4}{|l|}{ Gram +ve cocci } \\
\hline Streptococci pneumoniae & $10(10 \%)$ & $20(15 \%)$ & $25(17 \%)$ \\
\hline Alpha hemolytic streptococci & $27(28 \%)$ & $15(11 \%)$ & $10(7 \%)$ \\
\hline \multicolumn{4}{|l|}{ Beta hemolytic streptococci } \\
\hline Group A & $4(4.1 \%)$ & $8(6 \%)$ & $8(6 \%)$ \\
\hline Group B & $20(21 \%)$ & $25(16 \%)$ & $25(17 \%)$ \\
\hline Group C & $1(1 \%)$ & $5(4 \%)$ & $5(4 \%)$ \\
\hline Staphylococcus aureus & $10(10 \%)$ & $15(11 \%)$ & $17(12 \%)$ \\
\hline Staphylococcus epidermis & $10(10 \%)$ & $10(7 \%)$ & $10(7 \%)$ \\
\hline \multicolumn{4}{|l|}{ Gram -ve cocci } \\
\hline Neisseria & $4(4 \%)$ & $10(7 \%)$ & $10(7 \%)$ \\
\hline \multicolumn{4}{|l|}{ Gram -ve bacilli } \\
\hline Hemophilus influenza & $2(2 \%)$ & $10(7 \%)$ & $12(8 \%)$ \\
\hline Pseudomonas aeruginosa & $2(2 \%)$ & $10(7 \%)$ & $10(7 \%)$ \\
\hline Bacteroids & $5(6 \%)$ & $7(5.1 \%)$ & $7(5 \%)$ \\
\hline \multicolumn{4}{|l|}{ Yeast } \\
\hline Candida albicans & $2(2 \%)$ & $5(4 \%)$ & $5(3 \%)$ \\
\hline Total & 97 & 137 & 144 \\
\hline
\end{tabular}

Table-4: Antibiogram of different organisms in surface, aspirate and core

*St.pneu- streptococcus pneumoniae, a Hemo-Alpha hemolytic streptococci, GrpB St-GroupBBeta hemolytic streptococci, Saureus-Staphylococcus aureus, S epid-Staphylococcus epidermidis, Neiss-Neisseria, Hemo-Hemophilus influenza, van-vancomycin, lin-linezolid, tei-teicoplanin, ami-amikacin, pip \& taz-piperacillin and tazobactam, cipciprofloxacin, cef \& sul- cefaperazone and sulbactam, cef-ceftriazone, azi-azithromycin, cefi-cefipime, gen-gentamycin, amox-amoxicillin. 
Original Research Article

\begin{tabular}{|c|c|c|c|c|c|c|c|c|c|c|c|c|}
\hline Org & $\begin{array}{l}\text { Van } \\
(\%)\end{array}$ & $\begin{array}{l}\text { Lin } \\
(\%)\end{array}$ & $\begin{array}{l}\text { Tei } \\
(\%)\end{array}$ & $\begin{array}{l}\text { Ami } \\
(\%)\end{array}$ & $\begin{array}{c}\text { Pip \& } \\
\text { taz } \\
(\%)\end{array}$ & $\begin{array}{l}\text { Cip } \\
(\%)\end{array}$ & $\begin{array}{c}\text { Cef \& } \\
\text { sul } \\
(\%)\end{array}$ & $\begin{array}{l}\text { Cef } \\
(\%)\end{array}$ & $\begin{array}{l}\text { Azi } \\
(\%)\end{array}$ & $\begin{array}{l}\text { Cefi } \\
(\%)\end{array}$ & $\begin{array}{l}\text { Gen } \\
(\%)\end{array}$ & $\begin{array}{c}\text { Amo } \\
\mathbf{x} \\
\%)\end{array}$ \\
\hline \multicolumn{13}{|l|}{ St.pneu } \\
\hline Surf & 95 & 94.3 & 93.3 & 81 & 83.6 & 76.4 & 82 & 66 & 56 & 55 & 75 & 80 \\
\hline Asp & 94.7 & 92 & 94.7 & 82.5 & 85 & 77 & 84.7 & 67.7 & 54 & 54 & 76 & 81.6 \\
\hline Core & 93.9 & 93.6 & 96 & 83 & 86.6 & 78.9 & 85 & 67 & 53.8 & 55.5 & 76 & 82.5 \\
\hline \multicolumn{13}{|l|}{$\alpha$ Hemo } \\
\hline Surf & 95.4 & 91 & 93.2 & 81.2 & 80.6 & 70.2 & 83 & 60.1 & 55.7 & 54 & 77 & 82.4 \\
\hline Asp & 94.2 & 92.9 & 92.1 & 82 & 82.3 & 74.3 & 82.3 & 63.3 & 56 & 53.2 & 74 & 83.6 \\
\hline Core & 93 & 92 & 93 & 80.1 & 83 & 75 & 83 & 67 & 53.8 & 52.1 & 79 & 89 \\
\hline \multicolumn{13}{|c|}{ GrpB St } \\
\hline Surf & 90.3 & 85.1 & 89 & 79.2 & 77.2 & 71 & 82.1 & 55 & 56 & 53 & 71 & 83.7 \\
\hline Asp & 94.9 & 88 & 90.1 & 80.2 & 79 & 73.4 & 84.7 & 58.1 & 58.5 & 56 & 77 & 85.1 \\
\hline Core & 93.1 & 89.1 & 92 & 79 & 81 & 74.2 & 88.1 & 60 & 60 & 59.4 & 79 & 86 \\
\hline \multicolumn{13}{|l|}{ Saureus } \\
\hline Surf & 91.7 & 90.6 & 90 & 78.7 & 77.7 & 80.3 & 85 & 60 & 59 & 55.3 & 74 & 84.8 \\
\hline Asp & 93 & 92.1 & 90.2 & 77.1 & 78.1 & 83.5 & 86.3 & 61.5 & 57.7 & 54.9 & 77.9 & 86.1 \\
\hline Core & 93.7 & 90 & 91 & 78 & 78 & 85 & 88.1 & 60 & 55 & 57 & 80 & 87.2 \\
\hline \multicolumn{13}{|l|}{ S epid } \\
\hline Surf & 94.6 & 92.5 & 90.4 & 77.4 & 76.1 & 80.2 & 87.3 & 66.2 & 55.2 & 58 & 82.3 & 88.2 \\
\hline Asp & 95.8 & 94.8 & 91.2 & 78.2 & 77 & 81 & 88 & 67.1 & 57.9 & 59.3 & 84.6 & 89.1 \\
\hline Core & 96 & 97 & 90 & 78 & 75 & 82.4 & 88.1 & 70 & 60 & 60 & 85 & 88 \\
\hline \multicolumn{13}{|l|}{ Neiss } \\
\hline Surf & 94.2 & 80.2 & 79.2 & 71.3 & 69.6 & 77.5 & 73.4 & 70.6 & 51 & 56.3 & 77.1 & 79.1 \\
\hline Asp & 94 & 85 & 78.4 & 72 & 69 & 78.7 & 76.1 & 75.2 & 54 & 58 & 76 & 78.4 \\
\hline Core & 96.4 & 85.1 & 79.5 & 77 & 70 & 79 & 75 & 74.4 & 52.6 & 57.9 & 78.4 & 76 \\
\hline \multicolumn{13}{|l|}{ Hemo } \\
\hline Surf & 86 & 84.9 & 86.1 & 78.3 & 70.5 & 71.8 & 75.3 & 66 & 77 & 70.5 & 75.3 & 81 \\
\hline Asp & 88 & 85 & 87 & 77.4 & 69 & 71 & 77 & 67.4 & 75.3 & 73.5 & 73.7 & 83.5 \\
\hline Core & 87.3 & 82 & 88.5 & 77.4 & 69.3 & 73.3 & 76.5 & 68 & 76.1 & 76 & 76 & 83 \\
\hline
\end{tabular}

\section{Discussion}

Chronic tonsillitis, resistant to penicillin therapy is a major medical problem in all age groups. The inability of penicillins to eradicate the infection is becoming increasing clinical concern, accounting for up to $25 \%$ of cases, in some reports of acute pharyngo-tonsillitis [7]. Various theories have been proposed to explain the failure of penicillin therapy. One of the most popular is the $\beta$-lactamase produced by bacteria harbored in the tonsil core tissue may protect penicillin-susceptible strains, as has been shown both in vitro and in vivo [8].
These organisms, present in the deep tissue, may not be apparent on superficial sampling, since recurrent infection impairs drainage of the tonsillar crypts [9], thus impeding the progress of bacteria from the core to the surface and resulting in a negative swab [10]. Antibiotics alter the balance of the normal flora and enhance the acquisition of $\beta$-lactamase producing bacteria which leads to chronic infection of the tonsils, with irreversible pathologic changes, and the need for surgical intervention $[11,12]$. 
Common aerobic organisms isolated were, Streptococcus viridans, group A, $\beta$-hemolytic Streptococci, Streptococcus pneumoniae, Staphylococcus aureus, Haemophilus influenzae type B, and group B $\beta$ hemolytic Streptococci [1].

Surow et al., (1989) noted that tonsillar disease may arise from the bacteria within the substance of the tonsil rather than bacteria identified on the surface. They added that the surface of the tonsils is consistently exposed to oral secretions with their attendant flora. A small group of patients showed pathogen on the surface and a different pathogen in the core [13].

In the present study Group B hemolytic streptococcus, Streptococcus pneumonae and Staphlococcus aueus were the predominant microbes isolated in the aspirate and tonsil core tissue in outpatient population. Whereas Alpha hemolytic streptoccus and Group B hemolytic streptococcus were predominantly seen in tonsillar surface. Organisms isolated from the surface were normal commensals of oral cavity Superficial tonsillar swabs are often used as a guide in the selection of therapy in acute and chronic tonsillitis.

Since several studies showed marked discrepancy in the external and the core tonsillar pathogenic flora $[4,5,14$, $15,16]$. So antibiotic therapy according to superficial tonsillar surface swab leads to inadequate therapy and antibiotic resistance to various drugs in the due course of time.

Whereas Fine needle tonsil aspiration has potential in the treatment of tonsillitis patients; in particular, for patients with acute and chronic tonsillitis who fail to respond to initial penicillin therapy. But noncompliance, inadequate dosage, resistant bacteria, and reinfection should be considered [9].

Superficial tonsil swabs failed to recognize the presence of $H$ influenzae in a significant number of cases, including ß-lactamase producing strains, while the results of needle tonsil aspiration corresponded exactly with the core tonsil growth. Brook et al, De dio et al and Brodsky et al have found a high incidence of $H$. influenzae in the tonsil core tissue $[4,14,15]$.

The rate of isolation of $\mathrm{H}$. influenzae was also high in recurrently inflamed and hypertrophic tonsils studied by Kielmovitch et al. in 1989 [17]. However, the decline in the recovery of $\mathrm{H}$. influenzae type $\mathrm{b}$ and the concomitant increase in the recovery of $\mathrm{H}$ influenzae non-type b may be due to prior immunization with $H$. influenzae type $\mathrm{b}$ vaccine. The implementation of immunization against $H$. influenzae type $\mathrm{b}$ was associated with a decline in the incidence of this organism and an increase in rates of disease due to nontype b strains [15]. Fine needle aspiration may have benefit in the many young children who undergo surgery for conditions, such as chronic otitis media with effusion, related to and possibly caused by chronic infection of the tonsils. Appropriate antibiotic therapy given in the earlier stages prevents further complications [9].

In a study conducted by Agrawal et al. on all age group patients, common causative organisms isolated from the tonsillar surface were alpha-hemolytic Streptococci, Staphylococcus aureus, non-pathogenic Neisseria species, Haemophilus influenza, Pneumococcus, Enterococcus, Bacteroid fragilis, and Corynebacterium species. No anaerobes were identified [16].

In another study by Omer et al. in Turkey, an isolated the facultative and obligate anaerobes from the surface and core of patients with recurrent tonsillitis [18].

Anaerobic organisms were not isolated in the present study so further studies should be done to evaluate the other organisms. Limitations of the study include bleeding from the site of aspiration, pain during the procedure, infection and aspiration cannot be done in uncooperative patients.

The present results clearly demonstrate that, unlike the superficial tonsil swab, needle aspiration gives a representative picture of the tonsil core bacterial content in patients undergoing tonsillectomy for recurrent tonsillitis. Tonsil aspiration was found to be a simple, reliable, and low-cost procedure that may have benefit in the diagnosis and treatment of recurrent tonsillitis.

This is a new study where fine needle aspiration from the core of tonsil and organisms from core of tonsil are similar so clinician can do a simple aspiration from the tonsillar core and prescribe appropriate antibiotics to the patient which prevents antibiotic resistance, inadequate dosage, reinfection and the need for tonsillectomy in chronic tonsillitis patient.

\section{Conclusion}

Tonsil Tonsil core needle aspiration in patient would give a clear indication of the tonsil core pathogens, which is better than tonsil surface swab culture, and act as a better guide to appropriate antibiotic therapy. Patients complaining of infrequent but troublesome tonsillitis, in whom tonsillectomy is not as yet 


\section{Original Research Article}

warranted, may also benefit from this procedure. It is possible, but unproved, that specific antimicrobial therapy against tonsil core pathogens at this early stage may prevent the progression to recurrent infection or the development of large obstructive tonsils, thus lessening the need for surgery.

Adequate therapy given early in the disease process, before the occurrence of irreversible parenchymal changes prevent infection and the need for tonsillectomy.

Fine needle aspiration of core tonsil is a simple OPD procedure which helps in appropriate culture based antibiotic therapy in chronic tonsillitis, thus preventing unwarranted Tonsillectomy procedures in young children.

\section{What study adds to the existing to present knowledge?}

Tonsil core needle aspiration is a better indicator in studying core pathogens in Chronic tonsillitis than surface swab from the tonsil.

Fine needle aspiration of core tonsil is a simple OPD procedure which helps in appropriate culture based antibiotic therapy in Chronic tonsillitis, thus preventing unwarranted Tonsillectomy procedures in young children.

\section{Author's contribution}

Dr. Sriram: Conceived, planned and carried out the experiment, and gave final shape to the research paper.

Dr. Ganesh Bala: Developed the theory, performed and supervised the project.

Dr. Swetha Lakshmi: Collected experimental samples, assisted in microbiological study and analytical commutations.

Dr. Jayendiran: Aided in interpreting the result and worked on the manuscript

Funding: Nil, Conflict of interest: Nil Permission from IRB: Yes

\section{References}

1.Kalaiarasi R, Subramanian KS, Vijayakumar C, Venk ataramanan R. Microbiological Profile of Chronic Tonsillitis in the Pediatric Age Group. Cureus. 2018;10 (9): e3343. doi: 10.7759/cureus.3343.
2. Jović M, Avramović V, Vlahović P, Veličkov A, Petrović V. Expression of CD34 and CD146 vascular markers contributes to the immunological function of the human palatine tonsil.Histology and histopathology. 2018; 33(3):261-268. doi: 10.14670/ HH-11-919

3. Parker NP, Walner DL. Trends in the indications for pediatric tonsillectomy or adenotonsillectomy. Int $\mathrm{J}$ Pediat Otorhinolaryngol. 2011;75(2):282-285. doi: 10. 1016/j. ijporl.2010.11.019. Epub 2010 Dec 18.

4. Brook I, Yocum P. Bacteriology of chronic tonsillitis in young adults. Arch Otolaryngol. 1984;110(12):803805. doi:10.1001/archotol.1984.00800380033009

5. Surow JB, Handler SD, Telian SA, Fleisher GR, Baranak CC. Bacteriology of tonsil surface and core in children.Laryngoscope. 1989; 99(3): 261-266. doi:10. 1288 / 0000 5537-198903000-00005

6. Rosen G, Samuel J, Vered I. Surface tonsillar microflora versus deep tonsillar microflora in recurrent acute tonsillitis. J Laryngol Otol. 1977;91(10):911-913. doi: https://doi.org/10.1017/S0022215100084553

7. Gastanaduy AS, Kaplan EL, Huwe BB, McKay C, Wannamaker LW. Failure of penicillin to eradicate group A streptococci during an outbreak of pharyngitis. Lancet. 1980;2(8193):498-502. doi:10.1016/s0140-6736 (80) $91832-2$

8. Brook I. The role of $\beta$-lactamase-producing bacteria in the persistence of streptococcal tonsillar infection. Rev Infect dis. 1984;6(5):601-607.

9. Timon CI, Cafferkey MT, Walsh M. Fine-needle aspiration in recurrent tonsillitis. Arch OtolaryngolHead \& Neck Surg. 1991;117(6):653-656. doi:10.1001 /archotol.1991.01870180089017

10. Everett MT. The cause of tonsillitis. Practitioner. 1979;223(1334):253-259.

11. Scheifele DW, Fussell SJ. Ampicillin-resistant Haemophilus influenzae colonizing ambulatory children: Epidemiology and implications for otitis media therapy.Am J Dis Child.1981;135(5):406- 409

12. Brook I, Gober AE. Emergence of Beta-lactamaseprod uci ng Aerobic and Anaerobic Bacteria in the Oropharynx of Children Following Penicillin Chemotherapy. Clinic Pediatr. 1984; 23(6):338-341. doi: 10.1001/archotol.1988. 01860180081036 


\section{Original Research Article}

13. Surow JB, Handler SD, Telian SA, Fleisher GR, Baranak CC. Bacteriology of tonsil surface and core in children. Laryngoscope. 1989;99(3): 261-266. doi:10. 1288/00005537-198903000-00005

14. DeDio RM, Tom LW, McGowan KL, Wetmore RF, Handler SD, Potsic WP. Microbiology of the tonsils and adenoids in a pediatric population. Arch Otolaryngol Head Neck Surg. 1988; 114(7):763-5. doi:10.1001/ archotol. 1988. 01860190067025

15. Brodsky L, Moore L, Stanievich J. The role of Haemophilus influenzae in the pathogenesis of tonsillar hypertrophy in children. The Laryngoscope. 1988;98 (10): 1055-1060.
16. Agrawal A, Kumar D, Goyal A, Gupta R, Bhooshan S. Bacteriological evaluation and their antibiotic sensitivity pattern in tonsillitis. IOSR J Dental Med Sc. 2014;13(3):51-55.

17. Kielmovitch IH, Keleti G, Bluestone CD, Wald ER, Gonzalez C. Microbiology of obstructive tonsillar hypertrophy and recurrent tonsillitis. Arch Otolaryngol Head Neck Surg. 1989;115(6):721-724. doi:10.1001/ archotol. 1989. 01860300075021

20. Develioglu ON, Ipek HD, Bahar H, Can G, Kulekci M, Aygun G. Bacteriological evaluation of tonsillar microbial flora according to age and tonsillar size in recurrent tonsillitis. Eur Arch Otorhinolaryngol. 2014; 271(6):1661-1665. doi: 10.1007/s00405-014-2898-5. Epub 2014 Feb 1.

\section{How to cite this article?}

Sriram G, Ganeshbala A, Swetha LM, Jayendiran S. A comparative microbiological study of surface, aspirate and core tonsillar flora in chronic tonsillitis. Trop J Ophthalmol Otolaryngol.2019;4(5):320-327.doi: 10.17511/jooo.2019.i05.03 